\title{
FIGURAÇõeS DE DISCENTES DE UM PROGRAMA DE FORMAÇÃO DE PROFESSORES NO ENSINO SUPERIOR DO BRASIL TRAÇANDO SEUS MODOS DE SER
}

FIGURES OF DISCIPLES OF A TEACHER TRAINING PROGRAM IN HIGHER EDUCATION IN BRAZIL TRACING YOUR WAYS TO BE

FIGURACIONES DE ESTUDIANTES DE UN PROGRAMA DE FORMACIÓN DE PROFESORES DE EDUCACION SUPERIOR DE BRASIL TRAZADO DE SUS MODOS DE SER

\section{Samuel Pires Melo ${ }^{\mathrm{I}}$ \\ Leonam Costa Oliveira \\ Jullyane Frazão Santana}

\begin{abstract}
RESUMO: Neste estudo, procura-se traçar alguns vetores dos modos de ser de discentes de um curso do Plano Nacional de Formação de Professores (PARFOR) em uma Universidade Federal no Nordeste do Brasil. Trata-se de alunos com demanda diferenciada do proposto pelos cursos regulares do ensino superior brasileiro. Diante disso, questiona-se em que medida tais especificidades possibilitam situar processos identitários singulares. Utilizou-se abordagens dos tipos quanti e qualitativa, com aplicação de questionários e entrevistas, e análise dos dados pelos excel e mapas de associação de ideias. Os resultados indicam figurações gerais, mas também específicas em seus modos de ser que se constroem no processo de ingresso e permanência, a saber: familiar, espacial, de gênero, escolar, prática docente e perspectivas para o futuro. Isso permite dizer que esses discentes circunscrevem processos identitários sobre diversas teias de interação socioespacial.
\end{abstract}

PALAVRAS-ChaVE: Ensino superior. Discentes. Modos de ser. Formação de professores.

ABSTRACT: In this study, we try to trace some vectors of the ways of being of students of a course of the National Teacher Training Plan (PARFOR) at a Federal University in Northeast Brazil. These are students with differentiated demand from that proposed by the regular courses of Brazilian higher education. Faced with this, it is questioned to what extent these specificities make it possible to locate singular identity process. Quantitative and qualitative approaches were used, with application of questionnaires and interviews, and analysis of data by excel and maps of association of ideas. The results indicate general, but also specific, ways of being that are built in the process of entry and permanence, namely: family, spatial, gender, school, teaching practice and perspectives for the future. This allows us to say that these students circumscribe identity processes on diverse webs of socio-spatial interaction.

KEYWORDS: Higher education. Students. Modes of Being. Teacher Training.

RESUMEN: En este estudio, tratamos de sacar algunas vectores de las formas de ser de los estudiantes en un curso del Plan Nacional de Formación Docente (PARFOR) en una Universidad Federal en el noreste de Brasil. Estos son los estudiantes con la demanda diferenciada propuesto por cursos regulares de educación superior brasileña. Por lo tanto, nos preguntamos en qué medida estas diferencias permiten situar los procesos de identidad única. Utilizamos tipos de enfoques cuantitativos y cualitativos, con cuestionarios y entrevistas, y análisis de Excel y mapas de asociación de ideas. Los resultados indican configuraciones generales, sino también específico en sus formas de ser que se construyen sobre la entrada y suspender el procedimiento, a saber: la familia, los espaciales, el género, la escuela, la enseñanza de la práctica y las perspectivas para el futuro. Esto

Submetido em: 20/03/2017 - Aceito em: 16/06/2017 - Publicado em: 06/07/2017. 
nos permite decir que estos estudiantes circunscriben procesos de identidad en diferentes redes de sociointeracción.

PAlABRAS ClAVE: Enseñanza superior. Estudiantes. Modos de ser. Formación del profesorado.

\section{INTRODUÇÃ̃O}

Com os processos de mudanças ocorridos nas sociedades contemporâneas, observa-se que a intensificação do capitalismo industrial e das demandas de formação do trabalhador na década de 1990 trouxeram novas exigências educacionais que se fizeram necessárias à expansão de Instituições de Educação Superior (IES). Dentre elas, a Lei no 9.349/96 (Lei Darcy Ribeiro) e as Leis $\mathrm{n}^{\circ}$ 9.131/95 e $\mathrm{n}^{\circ}$ 9.192/95, às quais propuseram políticas e ações como solução para a democratização do acesso ao ensino superior, como, por exemplo: Universidade Aberta do Brasil (UAB), Fundo de Financiamento ao Estudante do Ensino Superior (Fies), Programa de Bolsa Institucional de Iniciação à Docência (PIBID), Programa de Apoio a Planos de Reestruturação e Expansão das Universidades Federais (Reuni) e Programa Universidade para Todos (ProUni).

Outro projeto que, de certa forma, traz objetivos comuns à essas novas exigências educacionais é o Plano Nacional de Formação de Professores (PARFOR). Embora o princípio direto não seja à democratização do Ensino Superior, mas a formação de professores do ensino básico na área de atuação vislumbra-se que com tal plano um número significativo de professores passam a ter uma formação superior para atuar na educação de forma mais qualificada. Em seus princípios, o PARFOR visa:

(a) implementação de políticas de formação continuada dos professores que atuam na educação infantil (creches e pré-escolas), considerando a Lei 10.639/2003 e os princípios preconizados pelas Diretrizes Operacionais para a Educação Básica nas Escolas do Campo; (b) implementação de políticas voltadas para a formação continuada dos professores que atuam nos anos/séries iniciais do ensino fundamental, considerando, também, as especificidades das escolas do campo, em particular as escolas de organização multietária ou multisseriada e as áreas temáticas, tais como educação ambiental, educação para os direitos humanos, educação integral; (c) formulação e implementação de políticas voltadas para a formação continuada dos professores que atuam nos anos/séries finais do ensino fundamental visando integralmente à melhoria da qualidade de aprendizagem da leitura/escrita e matemática, considerando, também, as especificidades das escolas do campo além das seguintes áreas temáticas: educação ambiental, educação para os direitos humanos, educação integral e integrada; (d) a promoção da participação dos profissionais de serviço e apoio escolar em programas de formação continuada, considerando, também, as áreas temáticas, tais como educação ambiental, educação para os direitos humanos, educação integral e integrada (BRASIL, 2009, s/n).

Ao evidenciar a dupla perspectiva do PARFOR, de democratização e formação continuada de professores que atuam na rede básica, observa-se que esse plano possibilita situar os 
professores do Ensino Básico numa equidade, pelo menos, de formação Superior em todo o Brasil. Além disso, traz à tona um processo de reflexividade de suas práticas docentes. $\mathrm{Na}$ verdade, essa formação continuada possibilita verificar que "a identidade não é um dado adquirido, não é uma propriedade, não é um produto [...] é um lugar de lutas e de conflitos, é um espaço de construção de maneiras de ser e de estar na profissão" (NÓVOA, 1992, p.16).

Há de se considerar, por outro lado, que a reforma de expansão do Ensino Superior no Brasil revelou uma Educação, nessa modalidade, pouco eficiente em seu processo histórico, oscilando "entre os interesses das camadas populares por mais educação, e educação que assegurasse status, e os interesses das classes dominantes, que procuravam conter, de várias formas possíveis, as pressões dessas camadas" (ROMANELLI, 1978, p104).

Para se ter uma ideia, Zago (2006) ressaltou que menos de $10 \%$ das pessoas na faixa etária entre 18 e 24 anos estavam cursando o Ensino Superior. Segundo ela, esse percentual representa um dos índices mais baixos da América Latina, para época. Em outro estudo, Franco (2008) elenca as variações de discentes concluintes do ensino médio e ingressantes no ensino superior, destacando que, em 1980, mais da metade (65\%) dos concluintes do ensino médio chegaram ao ensino superior, enquanto em 2002, 55,8\% conseguiram. Ele conclui observando que "são cerca de 25 milhões de jovens entre 18 e 24 aos, ou seja, em idade de educação superior, que ainda não tiveram a oportunidade de realizá-la" (p. 58). Além da baixa representatividade de jovens que frequentam essa modalidade de ensino, ainda é interessante salientar outra forma de desigualdade presente, que é o papel da escolha do curso que o/a discente irá fazer, pois:

(...) falar globalmente de escolha significa ocultar questões centrais como a condição social, cultural e econômica da família e o histórico de escolarização do candidato. Para a grande maioria não existe verdadeiramente uma escolha, mas uma adaptação, um ajuste às condições que o candidato julga condizentes com sua realidade e que representam menor risco de exclusão (ZAGO, 2006, p. 232).

A escolha por determinado curso tem relação com a evasão das IES, isso porque esses ingressantes não se identificam com o curso. Em uma observação com daqueles ingressantes, o senso do Instituto Nacional de Estudos e Pesquisas Educacionais (INEP), analisados pelo Sindicato das Mantenedoras do Ensino Superior (SEMESP), verificou que a taxa de evasão anual em 2013 dos cursos presenciais atingiu o índice de 24,9\%, sendo 27,4\% na rede privada e $17,8 \%$ na pública. Nos cursos EAD, no mesmo ano, o índice chegou a 28,8\%, sendo $29,2 \%$ na rede privada e $25,6 \%$ na pública. Conforme Silva Filho et. al. (2007, p.642), "a evasão estudantil no ensino superior é um problema internacional que afeta o resultado dos sistemas educacionais. As perdas de estudantes que iniciaram, mas não terminaram seus cursos são desperdícios sociais, acadêmicos e econômicos".

(...) las estadísticas a nivel internacional evidencian importantes dificultades en los estudiantes para graduarse de la universidad. Alrededor de un $31 \%$ de quienes 
acceden al nivel terciario no obtienen una titulación equivalente a dicho nivel (...). Aun así, existen diferencias considerables entre los países en este indicador, por ejemplo, naciones como Estados Unidos, Nueva Zelanda, Suecia y México muestran que más del $40 \%$ de los estudiantes que acceden a educación terciaria no obtienen una titulación por primera vez (FONSECA; GARCÍA, 2016, p. 26)

$\mathrm{Na}$ verdade, assim como no âmbito internacional, acontece que "[...] são raríssimas as IES brasileiras que possuem um programa institucional profissionalizado de combate à evasão, com planejamento de ações, acompanhamento de resultados e coleta de experiências bemsucedidas." (SILVA FILHO et. al., 2007, p. 03)

Ao analisar os dados apresentados por Zago (2006); Franco (2008) e SEMESP (2015), observa-se que existe uma atualização da configuração do corpo discente no ambiente universitário. Speller (2010, p.6), observando essa reconfiguração do perfil discente, destacou que existe uma "necessidade de repensar as metodologias educacionais à luz do fato que boa parte dos nossos estudantes da educação superior brasileira está alterando rapidamente seu perfil de faixa etária, origem socioeconômica e suas expectativas". Evidencia-se que mais de $40 \%$ das matrículas no Ensino Superior são de estudantes com mais de 25 anos, em decorrência da expansão do ensino noturno (ZAGO, 2006).

A localização geográfica é observada por Zago (2006) como fator deslocador da legitimação da exclusão. Ela observa que foram identificadas pesquisas com universitários moradores da favela, cujo objetivo foi conhecer que elementos motivam jovens a desenvolver estratégias integradoras que se contrapõem ao processo de exclusão e assim adentrarem e permanecerem nas IES. "O que permite a alguns fugir ao círculo vicioso que leva à exclusão e à marginalidade" (p. 227).

Moraes et al. (2011) consideram importante identificar categorias que contribuam para analisar a atual situação dos estudantes do ensino superior brasileiro. Eles observaram que as categorias trabalho, família, assistência estudantil, além das características gerais do estudante (origem socioeconômica, perfil, relação com a universidade, etc.) são fundamentais para análise do Ensino Superior no Brasil.

O que se compreende são, segundo Moraes et. al. (2011), variações de grupos sociais que são atravessados cotidianamente para construir seus modos de ser. Muitos das camadas populares, por exemplo, em seus trabalhos, sofrem maiores desgastes físicos, alimentam-se precariamente e não encontram tempo suficiente para repouso. Por outro lado, para muitos destes, o trabalho confere a possibilidade de se frequentar o curso superior, o que configura, de certa maneira, momentos de autonomia para aqueles que ainda não se tornaram completamente independentes de seus familiares. Ao se referir a familiares, é necessário destacar que possuem papel fundamental na vida de muitos destes estudantes. Constata-se 
este fato, na medida em que o grau de escolaridade dos pais influencia (economicamente e/ou emocionalmente) na "escolha" das carreiras dos filhos:

[...] a política de assistência estudantil é de fundamental relevância para a construção e aprimoramento de habilidades, na superação de algumas dificuldades que interferem na formação profissional, além de poder contribuir na educação, qualificação e preparação do estudante para o mercado de trabalho (Moraes et al., 2011, p. 215)

Ao delinear categorias para compreender o perfil de discentes do Ensino Superior, Moraes et al. (2011) procura uma objetivação do modo de ser deste grupo social. Principalmente porque traçam sentidos claros nas formas como atravessam os espaços sociais, desde o âmbito familiar aos demais espaços públicos. "Tal proposta tem como objetivo central identificar o perfil dos estudantes [...], analisando as principais dificuldades encontradas pelos discentes que interferem no processo de ensino/aprendizagem durante sua formação profissional." (p. 216). Por outro lado, Marinho (2013, p. 14378) chama atenção para as especificidades dos alunos e a maneira como estão circunscritos, pois:

[...] o PARFOR está inserido objetivamente numa complexa rede de inter-relações e seus cursistas, sujeitos desse processo, ocupam determinada condição na tessitura sociocultural na qual se inserem, de modo que, constantemente, estamos indagando se o PARFOR se constitui uma política de corte educacional que atende às demandas, necessidades e interesses da população, por intermédio dos canais e instâncias políticas para a verdadeira expressão de fortalecimento de indicadores educacionais, ou se ainda estamos vivenciando práticas resultantes de uma ação condicionante de treinamento de professores, baseado em objetivos massivos, temporais de gestão política e neoliberalizantes.

Mais do que o argumento do PARFOR se constituir como uma política educacional de formação continuada, o mais interessante nos argumentos levantados por Marinho (2013) é a complexa rede de inter-relações desses cursistas, como sujeitos do processo. O que nos leva a pensar na perspectiva histórico-crítica de Saviani (2005), com a problematização, a instrumentalização, a catarse e a prática social. Esse autor busca articular, a partir dos pressupostos teóricos da perspectiva histórico-social, uma reflexão que denote um processo educativo que articula a aprendizagem do aluno à formação do professor. Nesse sentido, indaga-se em que medida tais especificidades possibilitam situar processos identitários singulares aos/as alunos/as do PARFOR de um campus universitário situado no interior do Nordeste do Brasil?

\section{METODOLOGIA}

Este estudo tem caráter quanti e qualitativo. A escolha por esses tipos de pesquisa foi feita porque essas abordagens permitem dialogar com o campo de maneira relacional, entre dados objetivos e subjetivos a serem observados no campo de estudo e na análise das informações. Os elementos da abordagem quantitativa abrange um conjunto de procedimentos, técnicas e 
algoritmos destinados a auxiliar o pesquisador a extrair de seus dados subsídios para responder à(s) pergunta(s) que o mesmo estabeleceu como objetivo(s) de seu trabalho (FALCÃO; RÉGNIER, 2000, p. 232). Particularmente usamos os dados ordenados e categorizados para colocar em classificações (classes) e verificar sua frequência nas classes, bem como inserir numa forma que mostra sua posição relativa segundo alguma característica. Por outro lado, com a perspectiva qualitativa, buscamos uma compreensão aprofundada dos fenômenos estudados pela interpretação que as pessoas dão a alguns dos seus significados (MINAYO, 2006).

Por essa perspectiva, foram analisadas as experiências dos alunos durante o primeiro e terceiro semestres de uma turma do curso história do PARFOR Presencial, de primeira licenciatura. No primeiro semestre, foram aplicados questionários com 26 dos 33 alunos matriculados. No terceiro semestre, foram realizados questionários, entrevistas informais e observações em sala de aula, com temas-chave por este pesquisador.

O perfil dos entrevistados foi construído pela primeira fase (fevereiro a julho de 2016). No segundo momento, procuramos analisar as informações dos novos questionários, das entrevistas informais e observações realizadas sobre os temas do primeiro semestre através do perfil traçado. As análises foram realizadas a partir de mapas de associação de ideias de Spink (1999). Na verdade, utilizamos uma adaptação do recurso dos mapas de associação de ideias, que com as análises dos questionários de perguntas abertas, entrevistas informais e observação direta, foi possível estruturar o norte para guiar a disposição das respostas, buscando assim a produção de sentidos em torno de temáticas que vislumbraram seus modos de ser, a saber: a trajetória familiar, espacial, de gênero, escolar, prática docente e perspectivas para o futuro.

Na pesquisa da primeira fase, de um total de 31 matriculados, 26 deles estavam presentes no momento da aplicação, sendo seis do sexo masculino e 20 do feminino. A idade variou de 19 a 49 anos. No ano subsequente (2017), os mesmos foram convidados a responder um novo grupo de questões, entretanto, apenas 21 alunos continuavam a frequentar o curso. Desse total, 19 se encontravam em sala de aula e colocaram-se a disposição para participar da pesquisa. Nesse segundo grupo, observou 16 mulheres e dois homens, com idade que variou dos 21 a 50 anos.

\section{ANÁLISE E DISCUSSõES}

Tomando como base as informações obtidas por meio da análise de questionários respondidos pelos estudantes ingressantes no período 2016.1, no curso de História do PARFOR/UFPI, buscamos no primeiro momento desta análise traçar o perfil dos sujeitos pesquisados, pois ele nos coloca diante de uma perspectiva de regularidade situacional de estudantes de graduação 
de uma Universidade Federal do Brasil, mas também da forma como as políticas educacionais, neste caso pelo PARFOR, estão sendo circunscritas. O que traz inclusive margem para mensurar até que ponto a formulação de políticas e programas estão garantindo o processo de formação continuada, mas também democrática do ensino superior, meta traçada por elas próprias. Além disso, esse perfil possibilita situá-los dentro de certos grupos de identidades sociais.

Tabela 1. O perfil socioeconômico dos sujeitos entrevistados

\begin{tabular}{|c|c|c|}
\hline Características & $\mathbf{N}$ & $\%$ \\
\hline \multicolumn{3}{|l|}{ Idade (anos) } \\
\hline Total & 26 & 100 \\
\hline $19-24$ & 07 & 27,0 \\
\hline $25-39$ & 16 & 61,5 \\
\hline $40-49$ & 03 & 11,5 \\
\hline \multicolumn{3}{|l|}{ Sexo } \\
\hline Masculino & 06 & 23,1 \\
\hline Feminino & 20 & 76,9 \\
\hline \multicolumn{3}{|l|}{ Cor } \\
\hline Branca & 10 & 38,5 \\
\hline Preta & 01 & 3,8 \\
\hline Parda & 15 & 57,7 \\
\hline \multicolumn{3}{|l|}{ Estado civil } \\
\hline Solteiro (a) & 11 & 42,3 \\
\hline Casado (a)/mora junto & 15 & 57,7 \\
\hline \multicolumn{3}{|l|}{ Renda (salário mínimo) } \\
\hline Menos de 1 salário & 03 & 11,5 \\
\hline 1 a 2 & 17 & 65,4 \\
\hline De 3 a 5 salários & 06 & 23,1 \\
\hline Não sabem & 01 & 1,00 \\
\hline
\end{tabular}

Fonte: pesquisa de campo, 2016.

Os dados apresentados na tabela 1, sobre o perfil etário dos graduandos, mostram que, em sua maioria, ingressaram no ensino superior após a idade dita "convencional", que vai dos 18 aos 24 anos. Duas situações podem ser assim elencadas: a maioria $(61,5 \%)$ possui mais de 24 anos (estão no intervalo de 25 a 39 anos), e um pequeno número tem mais de 39 anos $(11,5 \%)$, sobressaindo assim uma perspectiva de adultos alunos buscando sua primeira ou segunda formação através do PARFOR. No entanto, esse perfil não se aproxima do cenário nacional, pois, em 2014, 58,5\% dos estudantes de 18 a 24 anos estavam na faculdade (IBGE, 2015).

Ao trazer a discussão sobre gênero na tabela 1, observa-se no curso de história uma maior proporção de mulheres $(76,9 \%)$. Esse dado é interessante para analisar que essa proporção chega a ser maior do que a média nacional, de 54,7\% mulheres cursando o ensino superior no 
Brasil (INEP, 2014). Por outro lado, quando se pensa na cor, prevalece uma maior proporção de pardos $(57,7 \%)$ entre os pesquisados. Quando comparado aos dados de uma pesquisa realizada por Ristoff (2014), através dos dados do Exame Nacional de Desempenho do Estudante (ENADE), em média nacional, no curso de história tem-se uma prevalência de 14\% de pretos, enquanto nos alunos pesquisados neste ensaio, tem-se $3,8 \%$.

Ristoff (2014) revela ainda outra discussão pertinente sobre o perfil da renda familiar de estudantes universitários. Ele observou nos cursos de História e Pedagogia uma representação próxima de zero para faixa de renda familiar com mais de 30 salários mínimos. "Percebe-se, por fim, que é expressivo o contingente de estudantes do grupo de até 3 salários mínimos e da larga faixa de 3 até de 10 salários mínimos" (RISTOFF, 2014, p.737). No caso desta pesquisa, nenhum dos alunos de história do PARFOR tem renda familiar com mais de 5 salários. A maioria $(65,4 \%)$ deles tem renda familiar entre um e dois salários.

Situar o perfil socioeconômico desses sujeitos da pesquisa torna-se mais compreensível quando se contextualiza os processos que estão /vão circunscrevendo seus modos de ser. Por isso, será feito a contextualização das trajetórias escolares dos pesquisados para entender suas perspectivas circunscritas nas faixas etárias, gênero, cor, estado civil e renda familiar. Além disso, fazer essa relação possibilita também conhecer melhor seus enfrentamentos e projetos para o futuro, pois como afirmam Alves e Dayrell (2015, p.378) "Realizamos projetos diversos simultaneamente e o fazemos em movimentos de ida e volta, de avaliação e reavaliação das nossas ações, orientando-nos por metas que foram atingidas (ou não) e por perguntas que foram respondidas (ou não)".

Tabela 2. Trajetórias educacionais dos discentes do PARFOR

\begin{tabular}{|c|c|c|}
\hline Características & $\mathbf{N}$ & $\%$ \\
\hline \multicolumn{3}{|l|}{ Cursou seu $1^{\circ}$ grau } \\
\hline Integralmente em escola pública & 18 & 94,7 \\
\hline Integralmente em escola particular & 1 & 5,3 \\
\hline \multicolumn{3}{|l|}{ Modalidade do curso do $1^{\circ}$ grau } \\
\hline Regular & 17 & 89,5 \\
\hline Supletivo & 2 & 10,5 \\
\hline \multicolumn{3}{|l|}{ Concluiu seu $1^{\circ}$ grau em escola } \\
\hline Rural & 10 & 52,6 \\
\hline Urbano & 9 & 47,4 \\
\hline \multicolumn{3}{|l|}{ Cursou seu $2^{\circ}$ grau } \\
\hline Integralmente em escola pública & 18 & 94,7 \\
\hline Integralmente em escola particular & 01 & 5,3 \\
\hline \multicolumn{3}{|l|}{ Modalidade do curso do $2^{\circ}$ grau } \\
\hline Regular & 16 & 84,2 \\
\hline Supletivo & 03 & 15,8 \\
\hline
\end{tabular}

Concluiu seu $2^{\circ}$ grau em escola

\begin{tabular}{l|l|l|l|l|l|} 
Rev. Inter. Educ. Sup. & Campinas, SP & v.3 & n.2 & p.336-356 & maio/ago. 2017
\end{tabular}


Rural

Urbano
7

12

5

14

Sim

Não

Houve pausa entre Ensino Médio para Superior

Sim

Não

Houve pausa entre Ensino Fundamental para Médio

\section{im}

36,8

63,2

Fonte: pesquisa de campo, 2017.

A amostra em questão na tabela 2, compreende uma parcela da população oriunda das camadas populares e consumidora dos bens e serviços oferecidos pelo sistema público, isso porque, conforme essa tabela, dos respondentes, $94,7 \%$ concluiu o $1^{\circ}$ e o $2^{\circ}$ grau integralmente em escola pública, destaca-se que um percentual considerável destes evadiu de suas localidades de origem, iniciando o processo migratório logo nos anos iniciais de sua escolarização. Pois a maioria dos entrevistados nessa pesquisa advém de pequenos municípios ${ }^{2}$, que segundo Wanderley (2001) são espaços com população inferior ou igual a 20.000 habitantes que caracterizam-se por seu baixo grau de urbanização. Nesse sentindo, destaca-se a inexistência ou precariedade das escolas de educação básica nestas localidades.

Contudo, o fato de migrarem para outros espaços não garante a continuação ininterrupta dos estudos por parte destes sujeitos. O caminho por eles percorrido é permeado por inúmeras dificuldades, que corroboram com a evasão escolar na proporção que avançam nos níveis de ensino. Dentro dessa perspectiva, citamos Dayrell (2007, p.1124) que aponta para o fato de os jovens da camada popular buscarem mais que conhecimento, pois:

\begin{abstract}
Ao contrário da escola, já experimentam na pele o descentramento das instituições e demandam mais. Demandam redes sociais de apoio mais amplas, como equipamentos de lazer e cultura nos seus bairros, além de políticas públicas que os contemplem em todas as dimensões, desde a sobrevivência até o acesso aos bens culturais.
\end{abstract}

Muitos são inclinados ao mundo do trabalho, pois este proporciona o atendimento a condição juvenil, dando subsídios para a sua integração no mundo capitalista e globalizado, onde é de suma importância para a integração nas mais variadas redes de sociabilidade estar/ ser das tecnologias digitais de valores consumistas, o que exige do indivíduo aparelhos eletrônicos modernos, vista-se com roupas de marca, consuma produtos com alta aceitação no mercado e tenha condições de frequentar certos espaços.

\footnotetext{
${ }^{2}$ Os pequenos municípios citados por eles no levantamento de dados do primeiro semestre do curso foram: no Estado do Maranhão - Araioses, Santana do Maranhão, Tutoia e São Bernardo - e no Estado do Piauí - Luís Correia.

\begin{tabular}{|l|l|l|l|l|l|} 
Rev. Inter. Educ. Sup. & Campinas, SP & v.3 & n.2 & p.336-356 & maio/ago. 2017 \\
\hline
\end{tabular}
}


Outro aspecto a ser apontado como fator que leva os jovens rurais a evadirem dos bancos escolares é o choque cultural existente entre eles e os que tem origem no urbano, pois apresentam demandas distintas. Além disso, pesquisas como a de Paulo (2010, apud PAULO; SILVA, 2013, p.03) demostram que não há uma juventude rural, "mas uma multiplicidade de situações juvenis rurais que são delimitadas pelas condições socioeconômicas das famílias, acesso à educação, gênero e localização da comunidade onde mora em relação à cidade".

Em uma pesquisa realizada por Silva (2002, p.102) no município do Vale do Jequitinhonha, ela demostra que os jovens fazem suas escolhas mediante as vivencias postas no tempo presente, abandonando a escola porque:

Muitas vezes, se veem num processo de sucessivas repetências, seja porque têm de migrar para completar a renda familiar; abandoná-la, temporariamente, para ajudar os pais no plantio quando chega o período de chuvas; ou porque a escola que têm não lhes oferece perspectivas de futuro profissional, principalmente no momento de entrada no mercado de trabalho; seja pelo acontecimento de uma gravidez precoce. $\mathrm{O}$ que significa dizer que o projeto individual de futuro vai ficando cada vez mais distante.

No caso dos alunos da presente pesquisa, conforme tabela 2, um percentual de 26,3\% após concluírem o ensino fundamental não iniciaram o médio logo em seguida, sendo que os motivos mais recorrentes, neste caso, versam a falta de interesse, casamento e gravidez precoce. Entretanto, quando falamos em termos de conclusão do ensino médio e ingresso no ensino superior, este percentual quase triplica, sendo estimado que 63,2\% deram "pausas" em seus estudos ao migrarem para este nível de ensino mais avançado. Além da justificativa acima, declaram que a falta de recursos e de oportunidades foram fatores preponderantes para este hiato em suas trajetórias educacionais.

Tabela 3. Escolaridade dos pais ou responsáveis dos pesquisados

\begin{tabular}{lcc}
\hline Características & $\mathbf{N}$ & $\mathbf{\%}$ \\
\hline Pai & 19 & 100 \\
Analfabeto & 06 & 31,6 \\
Sabe ler, mas não foi a escola & 01 & 5,3 \\
Fundamental incompleto & 07 & 36,8 \\
Fundamental completo & 01 & 5,3 \\
Ensino médio completo & 01 & 5,3 \\
Não sabe & 02 & 10,5 \\
Mãe & & 15,8 \\
Analfabeta & 03 & 26,3 \\
Sabe ler, mas não foi a escola & 05 & 36,8 \\
Fundamental incompleto & 07 & 5,3 \\
Fundamental completo & 01 & 10,5 \\
Ensino médio completo & 02 & 5,3 \\
Não sabe & 01 &
\end{tabular}

Fonte: pesquisa de campo, 2017. 
Pertinente ao exposto, concordamos com Zago (2006, p.230) ao considerar que "a desigualdade de oportunidades de acesso ao ensino superior é construída de forma contínua e durante toda a história escolar dos candidatos". Sendo o capital cultural e econômico fundamentais para o ingresso em níveis mais altos de escolaridade, bem como para a escolha do curso e continuidade no mesmo. Esse argumento levantado pela autora tem relação com a trajetória dos pais dos pesquisados, pois nenhum deles tem pai ou mãe com Ensino Superior incompleto e nem completo. Na verdade, a maioria não tem nem o fundamental completo, como pode ser observado na tabela 3 .

Tais questões trazem para a discussão as disparidades entre o aumento do número de vagas nas universidades públicas e o acesso da população que depende prioritariamente dessa modalidade de ensino, elucidando as desigualdades sociais postas atualmente e a ausência de políticas públicas que garantam uma trajetória escolar de qualidade desde os primeiros anos da educação até a entrada do indivíduo no mercado de trabalho, garantindo uma concorrência pautada na igualdade, como pode ser observada na fala de uma aluna.

Para eu ter que concluir meu ensino médio, antigo pedagógico, tive que ir trabalhar de empregada doméstica. Quando concluir, voltei para casa do meu pai, e me casei [...] passei em um concurso público, fiz uma faculdade [...] fiquei muito triste porque não pude receber meu diploma dessa faculdade porque não paguei todas as mensalidades, mas uma amiga me deu uma dica para negociar com eles e pedir um abatimento, foi quando consegui me formar [...] eu vim fazer história em uma universidade federal para mostrar para todo mundo que sou capaz de chegar onde quero [...] eu pretendo concluir meu curso (Discente, 38 anos, 2017).

Programas como o PARFOR, apesar de suas limitações, contribuem para a superação das barreiras educacionais vivenciadas por esta camada da população. Pois coloca nos bancos da academia sujeitos com perfis que destoam dos estudantes oriundos de classes média e alta. Tal iniciativa rompe com as tradicionais estatísticas de baixa escolaridade dessa população, traduzidas neste estudo pelo os níveis de escolaridade dos pais dos sujeitos entrevistados.

Tabela 4. Perspectivas para o futuro

\begin{tabular}{lcc} 
Características & $\mathbf{N}$ & $\mathbf{\%}$ \\
\hline Perspectivas para futuro & & 5,3 \\
Concurso público & 01 & 42,1 \\
Formação continuada & 08 & 26,3 \\
Concurso público/ Formação continuada & 02 & 10,5 \\
Concurso público/ Formação continuada e voltar à localidade & 02 & 10,5 \\
Concurso público/ Formação continuada e atuar em outra área & & \\
Mudanças com a formação superior & 08 & 47,4 \\
Melhorar condição financeira e da família & 01 & 52,6 \\
Orgulho para família/ comunidade & 09 & 47,4 \\
Realizar conquistas pessoais e profissionais & &
\end{tabular}

Fonte: pesquisa de campo, 2017 
Nessa linha de discussão, pela verificação da relação entre a tabela 3 com a 4, podemos analisar que os participantes do estudo, diferindo de seus pais ou responsáveis, pensam em diferentes perspectivas para seu futuro. E dentro dessa mudança, 5,3\% deles pretendem apenas prestar concurso público, todos os demais respondentes apostam na formação continuada, sendo que 47,4\% só vislumbram está última opção. Há de se observar ainda que $26,3 \%$ a considera somada ao concurso público, $10,5 \%$ pretende continuar estudando, prestar concurso e retornar ao local de origem e outros 10,5\% tanto continuará estudando, como prestará concurso e atuará em outras áreas. Com relação as mudanças esperadas através da formação superior, os estudantes visam melhorar a condição financeira e/ ou ajudar a família (47,4\%), Tornar-se orgulho e/ou exemplo de transformação para a família e comunidade $(5,3 \%)$ e realizar conquistas pessoais e profissionais $(47,4 \%)$. Esse emaranhado de projeções tomam sentido na seguinte fala:

\begin{abstract}
Eu sou professora substituta na educação infantil, mas todo ano é sempre essa insegurança se você vai continuar na secretaria de educação, se vai continuar na mesma escola [...] por isso quero terminar meu curso para fazer um concurso e garantir minha estabilidade [...] é muito difícil, mas queria, além de passar no concurso, também trabalhar perto de casa [...] seria perfeito para mim [...] ah, tenho sim interesse em, quem sabe, fazer um mestrado, mas pelo menos a especialização, vou fazer também (Discente, 29 anos, 2017).
\end{abstract}

A tabela 4 mostra ainda que os modos de ser dos atores sociais que constituem o estudo em questão são influenciados pelos seus múltiplos espaços de vivencia, neste caso, Castro (2009), aponta que é indispensável para a análise que os consideremos principalmente com base nos processos de interação social. Somado a isso, é interessante observar como estudantes do PARFOR se sentem nesses múltiplos espaços, inclusive por muitos se fazerem no fluxo entre espaços rurais e urbanos. Para se ter uma ideia sobre o modo como estão vivenciando esses processos, observamos a leitura de uma dessas estudantes, que mora no meio rural, mas com transito contínuo no espaço urbano, inclusive por estar na Universidade,.

Eu pensei muitas vezes em desistir dessa universidade, é muito diferente do que eu pensava que era aqui [...] porque tudo bem da gente ser mal visto nessas lojas da cidade [...] eu achava que as pessoas da universidade eram mais gente boa [...] porque diz que é onde se educa, né? [...] tipo, eu acreditava que professor da Universidade era muito educado e respeitador [...] foi quando eu vi uma cena que vai ficar marcado para sempre na minha vida, uma professora dizendo que 'alunos do parfor não podem ter os mesmos direitos dos demais alunos daqui' [...] isso acabou comigo, já achava diferente e muito mais difícil nós estarmos aqui porque é muito intenso, o tempo para nós é muito mais rápido, aí vem uma professora dizer isso [...] acabou comigo (Discente, 26 anos, 2017).

A maneira como os estudantes do PARFOR representam os espaços são orientados pelos modos de ser estruturados durante a vida, no caso da discente, percebemos uma diferenciação de perspectivas que desestruturou sua maneira de ver a Universidade, principalmente porque ela presenciou aspectos da cultura universitária que ela não esperava encontrar. Ela imaginou que as interações sociais estariam minimamente relacionadas ao meio rural, como viver em

n. 2


comum, em que a proximidade contribui para um sentimento mútuo de confiança e solidariedade. Por outro lado, devemos destacar que há também pessoas vivenciando no espaço universitário possibilidades de construir/ projetar outras dimensões.

Tabela 5. Laços de pertencimentos em espaços

\begin{tabular}{lcc}
\hline Características & N & \% \\
\hline Sente-se bem na UFPI & 16 & 84,2 \\
Sim & 03 & 15,8 \\
Não & & \\
& & \\
Tem orgulho ser aluno da UFPI & 17 & 10,5 \\
Sim & 02 & \\
Não & & 89,5 \\
Posso contar com meus professores da UFPI & 17 \\
Sim & 02 & 10,5 \\
Não & & \\
Confio nos colegas da minha turma & 19 & 100,0 \\
Sim & 00 & 0,0 \\
Não & & \\
Costuma frequentar igreja/ templos religiosos & 08 & 42,1 \\
Sim & 08 & 42,1 \\
Não & 03 & 15,8 \\
Não respondeu & & 89,5 \\
Sinto que pertenço a minha localidade/ cidade & 17 & 10,5 \\
Sim & 02 & \\
Não & & 57,9 \\
Confio nas pessoas de minha localidade/ cidade & 11 & 36,8 \\
Sim & 07 & 5,3 \\
Não & 01 & \\
Não respondeu & & \\
\hline
\end{tabular}

Fonte: pesquisa de campo, 2017.

Podemos verificar, na tabela 5, na maioria dos discentes, que participaram da pesquisa, laços de confiança com a Universidade. Na verdade, uma grande proporção $(89,5 \%)$ tem orgulho de estudar nessa IES, sentem-se bem $(84,2 \%)$ na UFPI, podem contar com seus professores $(89,5 \%)$ e todos confiam em seus colegas de turma. Nesse sentido, vislumbramos uma relação de proximidade desses pesquisados com o espaço universitário, o que pode também ser visto no local de moradia deles, onde a maioria $(89,5 \%)$ sente que pertence a sua localidade/ cidade. Porém, há de considerar que esses discentes confiam mais no colegas de turma da UFPI (100\%) do que nas pessoas de suas localidades/ cidades (57,9\%). E menos da metade $(42,1 \%)$ frequenta a igreja/ templos religiosos. Isso tudo nos possibilita considerar que boa parte desses estudantes criaram mecanismos para se manterem na Universidade. Para Santos (2009, p. 70) existem dois mecanismos que possibilitam a permanência de alunos nas IES: 
É necessário dinheiro para comprar livros, almoçar, lancha, pagar o transporte, etc. Mas é necessário também o apoio pedagógico, a valorização da auto-estima, os referenciais docentes, etc. Sendo assim, entendemos que a permanência na Universidade é de dois tipos. Uma permanência associada às condições materiais de existência na Universidade, denominada por nós de Permanência Material e outra ligada às condições simbólicas de existência na Universidade, a Permanência Simbólica. Antes vale dizer que entendemos por condições simbólicas a possibilidade que os indivíduos têm de identificar-se com o grupo, ser reconhecido e de pertencer a ele.

É necessário compreender o quanto a permanência simbólica influencia os modos de ser desses estudantes. Para se ter uma ideia, eles criam um laço de interdependência muito forte entre os colegas justamente para suprir a necessidade da família, já que muitos tem que deslocar-se de sua comunidade, geralmente em municípios distantes, por vezes, mais de um mês ou fim de semana, como pondera uma dessas discentes:

Aqui é assim, nós brigamos, mas logo fazemos as pazes [...] não adianta querer ficar brigado porque nós vamos passar vários anos aqui, aí é melhor a gente resolver nossas diferenças [...] no começo foi difícil integrar a maioria [...] porque nós somos também de municípios distantes uns dos outros, aí nunca tínhamos nos visto, né? [...] elas são como irmãs para mim, bate uma saudade de casa, do meu marido, filhos [...] porque às vezes eu tenho que ficar o fim de semana aqui porque tenho aulas no sábado, e muito trabalho para fazer (Discente, 32 anos, 2017).

A fala da discente nos possibilita compreender que há uma completude entre os espaços da família e de amigos da Universidade, pois eles criam um alargamento do entendimento de família, e dos próprios laços de parentesco, que ultrapassam a perspectiva consanguínea. Por outro lado, é importante frisar que existe uma disposição da própria família dessa estudante que possibilita ultrapassar os estreitamentos dos laços para níveis elevados de coesão extrafamiliar.

Tabela 6. Laços familiares dos discentes

\begin{tabular}{lcc}
\hline Características & N & \% \\
\hline Posso contar com a ajuda da minha família & & 89,5 \\
Sim & 02 & 10,5 \\
Não & & 84,2 \\
Sinto que sou amado pela minha família & 16 & 5,3 \\
Sim & 01 & 10,5 \\
Não & 02 & \\
Não respondeu & & 17,5 \\
Sinto-me seguro com minha família & 17 & 10,5 \\
Sim & 02 & \\
Não & & \\
\hline
\end{tabular}

Fonte: pesquisa de campo, 2017.

A tabela 6 mostra o perfil dos laços familiares dos discentes pesquisados, onde tem-se que a maioria $(89,5 \%)$ pode contar com a ajuda da família, é amado por ela $(84,2 \%)$. Vale salientar 
que a proximidade desses discentes com a família possibilita observar o quanto ela é importante no processo de construção e manutenção de suas identidades. O que pode ser vislumbrado inclusive nas atividades de tempo livre, que são primordiais para o entendimento dos modos de ser desses universitários, pois concordamos com Paulo (2010, p.118) ao afirmar que elas são vistas como um "elemento importante para a vivência, reconhecido por inúmeros estudiosos", sendo seus espaços de ocorrência um importante construtor de "sentidos, sentimentos e delimitações de fronteiras (fluidas)".

Tabela 7. Atividades desenvolvidas no Tempo livre

\begin{tabular}{lcc}
\hline Características & N & \% \\
\hline Atividades: & 01 & 5,3 \\
Culturais & 05 & 26,3 \\
Político-sociais & 01 & 5,3 \\
Esportivas/lazer & 12 & 63,2 \\
Nenhuma & & \\
& & \\
O que fazem em momentos de entretenimento: & 12 & 63,2 \\
De tudo um pouco & 07 & 36,8 \\
Ficar em casa, Descansar, ler e assistir & &
\end{tabular}

Fonte: pesquisa de campo, 2017.

A relação família e lazer apresentam-se na tabela 7, como parte significativa $(36,8 \%)$ desses discentes, isso porque eles ficam em casa descansando, assistindo e lendo algo, mesmo que grande parte $(63,2 \%)$ faça de tudo um pouco nos momentos de entretenimento. No entanto, vale salientar que a maioria $(63,2 \%)$ desses discentes diz não realizar atividades de lazer porque as entendem como aquelas que envolvem estar em movimento e turismo.

Tabela 8. Tempo livre e tecnologias digitais

\begin{tabular}{|c|c|c|c|}
\hline \multicolumn{2}{|l|}{ Características } & $\mathbf{N}$ & $\%$ \\
\hline \multicolumn{4}{|l|}{ Meios de comunicação usado pelos discentes: } \\
\hline \multicolumn{2}{|l|}{ Celular pré e/ou pós pago } & 02 & 10,5 \\
\hline \multicolumn{2}{|l|}{ Canais de Tv aberto e/ou fechado } & 01 & 5,3 \\
\hline \multicolumn{2}{|l|}{ Celular, Tv e internet } & 05 & 26,3 \\
\hline \multicolumn{2}{|l|}{ nternet e $\mathrm{Tv}$ por assinatura } & 03 & 15,8 \\
\hline \multicolumn{2}{|l|}{ Internet } & 08 & 42,1 \\
\hline \multicolumn{4}{|l|}{ Pontos em que acessam à internet: } \\
\hline \multicolumn{2}{|l|}{ Ambiente familiar } & 10 & 52,6 \\
\hline \multicolumn{2}{|l|}{ Ambiente público } & 04 & 21,1 \\
\hline \multicolumn{2}{|l|}{ Ambos } & 04 & 21,1 \\
\hline \multicolumn{2}{|l|}{ Outros } & 01 & 5,3 \\
\hline \multicolumn{4}{|l|}{ Frequência de utilização da internet: } \\
\hline \multicolumn{2}{|l|}{ Uma ou duas vezes por mês } & 01 & 5,3 \\
\hline \multirow{2}{*}{\multicolumn{2}{|c|}{$\begin{array}{l}\text { Apenas aos finais de semana } \\
\text { De um a dois dias por semana }\end{array}$}} & 03 & 15,8 \\
\hline & & 03 & 15,8 \\
\hline \multicolumn{2}{|l|}{ Todos os dias } & 11 & 57,9 \\
\hline \multicolumn{2}{|l|}{ Não respondeu } & 01 & 5,3 \\
\hline Rev. Inter. Educ. Sup. & v. 3 & p.336-356 & maio/ago. 2017 \\
\hline
\end{tabular}




\title{
Tempo conectado à internet:
}

Menos de meia hora

De meia a uma hora

De uma a três horas

Não respondeu

\section{Atividades que realizam online:}

Trabalhos e/ou estudo

Fonte: pesquisa de campo, 2017.

Uma outra dimensão do modo de ser desses estudantes pode ser observada na relação do tempo livre com o uso das tecnologias digitais, presentes no cotidiano. Para se ter uma ideia, os seres humanos e suas atividades estão cada vez mais ligados ao manuseio desses aparatos tecnológicos, ao ponto de excluir do convívio social ou das teias de interação aqueles que oferecem uma certa resistência a uso destas. Diante disso, Almeida (2005, p.04) afirma que:

\begin{abstract}
Nos adaptamos a uma série de mudanças velozes e, diga-se, extremamente radicais nos nossos modos de agir e de pensar. Assistir a canais de TV internacionais, falar ao telefone com alguém que encontra-se do outro planeta, movimentar a conta bancária e, pela Internet, checar multas de trânsito, comprar discos, trocar mensagens com o outro lado do mundo, pesquisar e estudar são, atualmente, atividades rotineiras em diversas partes do mundo. Estamos, portanto, vivenciando uma nova realidade, que é fazer parte da Sociedade da Informação, também, denominada de Nova Economia ou Economia do Conhecimento.
\end{abstract}

Essa relação das tecnologias digitais nos modos de ser dos respondentes da presente pesquisa possibilita enxergar a contradição no entendimento e usos desses aparatos, como se observa na tabela 8. Quando questionados sobre a utilização da internet, a maioria $(94,7 \%)$ diz usar para fazer trabalho e/ou estudo, porém, ao indagar-se em sala de aula sobre a quantidade de alunos que usam redes sociais, a maioria disseram que sim, e em grande proporção para ver o que as pessoas estão fazendo, postar seus momentos e divertir-se. O principal aparato utilizado para se conectar à internet foi o celular, no qual a maioria $(57,9 \%)$ faz uso diário, outros dizem não se conectarem porque onde moram não têm cobertura móvel da telefonia.

Os aspectos levantados na tabela 8 evidenciam que as tecnologias digitais fazem parte, de alguma forma, dos modos de ser desses discentes. E dentre seus usos, existe o considerado formal e informal. Esse último é visto como entretenimento, principalmente porque as redes sociais, segundo Castells (2003), têm um papel importante na formação das novas interações sociais virtuais, ou comunidades virtuais pactuados por interesses específicos. Em suas palavras:

Essas redes online tornam-se formas de 'comunidades especializadas', isto é, forma de sociabilidade construída em torno de interesses específicos. Como as pessoas 
podem facilmente pertencer a várias dessas redes, os indivíduos tendem a desenvolver seu 'portfólios de "sociabilidade". (CASTELLS, 2003, p. 10).

Nesse sentido, é evidente que os usos das tecnologias digitais pelo entretenimento têm um contentamento entre esses discentes que também são docentes. No entanto, questiona-se em que medida a educação formal se apropria desse aparato tecnológico para que ele seja realidade nesses espaços de formal de forma envolver os discentes para trabalhos que envolvam habilidades recreativas, com jogos e brincadeiras?

\section{CONCLUSÃO}

As análises realizadas neste trabalho evidenciam que o Plano Nacional de Formação de Professores tem possibilitado atores sociais experenciar novas posições que ultrapassam espaços sociais e/ou identidades até então formadas, reconstruindo seus modos de ser. Além disso, o processo de articulação das aprendizagens até então focadas à própria formação inicial do ser professor é reconfigurado pelas posições de estudante universitário. Coloca-se sob um vertente reflexiva a formação do que era ser professor para o patamar do que quero ser como professor.

As experiências são vividas sob o olhar do trabalho do docente universitário, mas também sobre os dos colegas de turma, das suas rotinas, culturas profissionais, comunitárias e familiares. Percebe-se que estes discentes são atravessados pelas várias identidades a que estão circunscritos para chegar a uma educação em nível superior. Isso porque quando as pessoas falam sobre si mesmos, elas se envolvem em uma relação autoconstruída pela dinâmica entre a narrativa e identidade (instituída e em instituição): sem ela, essa relação não poderia ser conhecida, ou melhor, reconhecida como modos de ser de discentes do PARFOR.

É possível situar também graus de aproximação e distanciamento à esses processos que vão circunscrevendo os modos de ser desses universitários. $\mathrm{O}$ estreitamento dos laços são mais preponderantes na família, Universidade, tecnologias digitais, professores e colegas de turma. Eles interagem como teias de conexão que fortificam suas projeções, especialmente o desejo de continuar fazendo o curso na IES, superar os desafios dos próprios processos a que estão circunscritos, como também se projetar para ocupar outras posições sociais, como a estabilidade financeira e a própria formação continuada. No entanto, há de salientar que outros aspectos de suas vidas, como as pessoas da localidade/ cidade e a própria instituição religiosa, vão perdendo a conexão primeira e estabilizadora entre esses alunos.

O estudo possibilitou portanto apresentar a discussão do perfil de universitários de um curso do PARFOR no Nordeste do Brasil, como também o lugar que as teias de interdependência têm para superar as desigualdades sociais, tanto no percurso até a universidade quanto na

n.2


experiência dentro dela. Embora não se tenha privilegiado somente a dimensão subjetiva da vivência nesses espaços por estudantes cujo perfil socioespacial contrasta com aqueles predominantes em seus respectivos cursos de período regular, foi possível a partir de entrevistas informais e observação direta do pesquisador constatar que suas experiências universitárias se caracterizam pelo desejo de superação, reencontro do lugares, repensar os sentidos da escolarização, servir de exemplo para familiares mais jovens, fruição cultural, mobilidade social, etc., mas também sentimentos de desenraizamento, isolamento e inferioridade.

Além disso, o estudo possibilitou enxergar em uma perspectiva microssocial o quanto uma política educacional (des)estrutura os processos sociais, no sentido de ressignificar os modos de viver e trabalhar dos atores sociais. Há uma mobilização social, seja em termos de espaços micro ou macrossociais. Porém, outros estudos se fazem necessários para se observar os pontos de convergência e divergência que vão dando sentidos aos atores sociais participantes desse Plano Nacional de Formação.

\section{REFERÊNCIAS}

ALMEIDA, Sidia Fonseca. Novas tecnologias de informação e desenvolvimento humano sustentável. Qualitas Revista Eletrônica, v. 4, n. 1, 2006. Disponível em: $<$ http://revista.uepb.edu.br/index.php/qualitas/article/viewFile/44/36 >. Acesso em: 10 fev. 2017.

ALVES, Maria Zenaide; DAYRELL, Juarez. Ser alguém na vida: um estudo sobre jovens do meio rural e seus projetos de vida. Educação e Pesquisa, v. 41, n. 2, p. 375-390, 2015. Disponível em: <http://www.scielo.br/scielo.php?pid=S151797022015000200375\&script=sci_abstract\&tlng=pt>. Acesso em: 20 dez. 2016.

BRASIL. Decreto n ${ }^{\circ}$ 6.755, de 29 de janeiro de 2009: institui a Política Nacional de Formação de Profissionais do Magistério da Educação Básica. Diário Oficial da União, Brasília, DF, 29 de janeiro de 2009.

BRASIL. Lei no 9.131/95, 24 de novembro de 1995. Diário Oficial da União, Brasília, DF, 24 de novembro de 1995.

BRASIL. Lei no 99.192/95, 23 de novembro de 1995. Diário Oficial da União, Brasília, DF, 23 de novembro de 1995.

BRASIL. Lei no 9.349/96. , 20 de dezembro de 1996. Diário Oficial da União, Brasília, DF, 20 de dezembro de 1996.

BRASIL. INEP - Instituto Nacional de Pesquisas Educacionais. 2014. Disponível em: <http://portal.inep.gov.br/web/censo-da-educacao-superior>. Acesso em: 20 nov. 2016. 
CASTELLS, Manuel. A galáxia da Internet. Rio de Janeiro: Jorge Zahar, 2003.

CASTRO, Elisa Guaraná. Juventude rural no Brasil: processos de exclusão ea construção de um ator político. Revista Latinoamericana de Ciencias Sociales, Niñez y Juventud, v. 7, n. 1, p. 179-208, 2009.

DAYRELL, Juarez. A escola "faz" as juventudes? Reflexões em torno da socialização juvenil. Educação \& Sociedade, Campinas, v.28, n.100. p. 1005-1028- 2007. Disponível em: <http://www.scielo.br/pdf/es/v28n100/a2228100>. Acesso em: 15 out. 2016.

FALCÃO, Jorge Tarcísio da Rocha; RÉGNIER, Jean-Claude. Sobre os métodos quantitativos na pesquisa em ciências humanas: riscos e benefícios para o pesquisador. Revista Brasileira de Estudos Pedagógicos. Brasília, v. 81, n. 198, p. 229-243, maio./ago. 2000. Disponível em: < http://rbep.inep.gov.br/index.php/rbep/article/view/937>. Acesso em: 10 mar. 2017.

FERNANDES, Marinalva Nunes. Formação Docente: Algumas Reflexões sobre o Plano Nacional de Formação de Professores da Educação Básica-PARFOR. PLURAIS-Revista Multidisciplinar, v. 1, n. 3, 2013.

FONSECA, Gonzalo; GARCÍA, Fernando. Permanencia y abandono de estudios en estudiantes universitarios: un análisis desde la teoría organizacional. Revista de la Educación Superior, v.45, n.179. 2016. p.25-39. Disponível em: <http://dx.doi.org/10.1016/j.resu.2016.06.004>. Acesso em: 15 fev. 2017.

FRANCO, Alexandre de Paula. Ensino Superior no Brasil: cenário, avanços e contradições. Jornal de Políticas Educacionais. N. 4, pp. 53-63, Julho-Dezembro de 2008.

IBGE. Censo da Educação Superior. Uma análise do Censo Demográfico, 2010. Disponível em: 〈ces.ibge.gov.br/base-de-dados/metadados/inep/censo-da-educacao-superior.html>. Acesso em: ago. 2016.

IBGE. Censo da Educação Superior. Uma análise do Censo Demográfico, 2015. Disponível em: 〈ces.ibge.gov.br/base-de-dados/metadados/inep/censo-da-educacao-superior.html〉. Acesso em: ago. 2016.

MARINHO, Raimunda Ramos. Formação continuada de professores e PARFOR: uma experiência na UFMA. XI Congresso Nacional de Educação - EDUCERE, PUC-Paraná, Curitiba, 23 a 29/09/2013. Disponível em: <http://educere.bruc.com.br/arquivo/pdf2013/8592_5030.pdf >. Acesso em: 10 fev. de 2017.

MINAYO, Maria Cecília de Souza. O Desafio do Conhecimento: pesquisa qualitativa em saúde. $9^{\circ}$ ed. São Paulo, SP: HUCITEC. 2006.

MORAES, Carlos Antonio de Souza et al. O estudante do ensino superior: identificando categorias de análise. VÉRTICES, Campos dos Goytacazes/RJ, v. 13, n. 3, p. 205-218, set./dez. 2011. 
MORAES, Maria Christina Schettert. Perfil dos acadêmicos do PARFOR da UNICRUZ no ano de 2013: reflexões sobre uma prática pedagógica. XVI Seminário Internacional de Educação do Mercosul. UNICRUZ: Trevo de Cruz Alta. 2015. Disponível em: < https://www.unicruz.edu.br/mercosul/pagina/anais/2014/DIREITO\%20A\%20EDUCACAO/A RTIGO/ARTIGO\%20-\%20PERFIL \%20DOS\%20ACADEMICOS\%20DO\%20PARFOR\%20 DA\%20UNICRUZ\%20NO\%20ANO\%20DE\% 202013\%20REFLEXOES\%20SOBRE\%20U MA\%20PRATICA\%20PEDAGOGICA.PDF>. Acesso em: 20 mar. 2017.

NÓVOA, Antônio (org.). Vidas de Professores. Porto: Porto Editora, 1992.

NÓVOA, Antônio. Os professores: um "novo" objecto da investigação educacional? In: NÓVOA, Antônio. (Org.) Vida de professores. Portugal: Porto Editora, 1992.

PAULO, Maria de Assunção Lima de. As construções das identidades de jovens rurais na relação com o meio urbano em um pequeno município. 2010. Tese (Doutorado em Sociologia) - Centro de Filosofia e Ciências Humanas, Universidade Federal de Pernambuco, Recife, 2010.

PAULO, Maria de Assunção Lima de; SILVA, Cícero Natanael de Oliveira. Juventude rural e ensino superior: acesso, limites, possibilidades e transformações. In: XXIX Congresso Latino-americano de Sociologia, 2013, Santiago - Chile. XXIX Congresso Latinoamericano de Sociologia, 2013.

RISTOFF, Dilvo. O novo perfil do campus brasileiro: uma análise do perfil socioeconômico do estudante de graduação. Avaliação, Campinas; Sorocaba, SP, v. 19, n. 3, p. 723-747, nov. 2014.

ROMANELLI, Otaíza de Oliveira. História da educação no Brasil (1930/1973). Petrópolis: Vozes, 1978.

SANTOS, Dyane Brito Reis. Para além das cotas: a permanência de estudantes negros no ensino superior como política de ação afirmativa. Salvador. 2009. 214f. Tese (Doutorado em Educação) - Universidade Federal da Bahia, Salvador. Disponível em: <https:

//repositorio.ufba.br/ri/bitstream/ri/11778/1/Tese\%20\%20Dyane\%20Santos.pdf $>$. Acesso em: 03 maio 2017.

SAVIANI, Demerval. Pedagogia histórico-crítica: primeiras aproximações. 9 ed. Campinas, SP: Autores Associados, 2005.

SEMESP. Sindicato das Entidade Mantenedoras de Estabelecimentos de Ensino Superior no Estado de São Paulo. 2015. Disponível em:

<www.scielo.br/pdf/ccedes/v22n57/12005.pdf>. Acesso em: 16 out. 2016.

SILVA, Santuza Amorim da. Os novos estudantes de Licenciatura no contexto da expansão do Ensino Superior. Revista Educação em Foco. Ano 17 - n. 23 - julho 2014 - p. 59-84 
SILVA, Vanda. Jovens de um rural brasileiro: socialização, educação e assistência. Cad. CEDES [online]. 2002, vol.22, n.57, pp. 97-115. Disponível em: <www.scielo.br/pdf/ccedes/v22n57/12005.pdf>. Acesso em: 16 out. 2016.

SILVA FILHO, Roberto Leal Lobo e et.al. Evasão no Ensino Superior Brasileiro. Cadernos de Pesquisa Fundação Carlos Chagas. v. 37, n. 132. set. / dez. 2007. Disponível em: $<$ www.scielo.br/scielo.php?script=sci_arttext\&pid=S0100-15742007000300007>. Acesso em: 15 set. 2016 .

SOUZA, Maria Irene Pellegrino de Oliveira; ZANETTI, Rosângela Ramsdorf. Olhares sobre a formação de professores: relatos, reflexões e proposições. Londrina: UEL, 2016.

SPELLER, Paulo. Ensino superior: prioridades, metas, estratégias e ações. 2010. FLACSO rede livre. Disponível em: < Disponível em:

http://www.cedes.unicamp.br/seminario3/paulo_speller.pdf>. Acesso em: 12 nov. 2016.

SPINK, M. J. Práticas discursivas e produção de sentidos no cotidiano: aproximações teóricas e metodológicas. São Paulo: Cortez, 1999.

WANDERLEY, Maria de Nazareth Baudel. Urbanização e ruralidade: relações entre a pequena cidade e o mundo rural: estudo preliminar sobre os pequenos municípios em Pernambuco. Revista Nordeste: regionalismo e inserção global, v. 1, p. 05-32, 2001.

ZAGO, Nadir. Do acesso à permanência no ensino superior: percursos de estudantes universitários de camadas populares. Revista Bras. de educação, v. 11, n. 32, maio/ago. 2006. Disponível em: < http://www.scielo.br/pdf/rbedu/v11n32/a03v11n32.pdf>. Acesso em: 01 de jul. 2016.

\section{${ }^{\mathrm{i}}$ Sobre os autores}

\section{Samuel Pires Melo}

E-mail: samuelmelo@ufpi.edu.br / ORCID: http://orcid.org/0000-0003-0655-2917

Universidade Federal do Piauí - Brasil

Doutorado em Sociologia pela Universidade Federal de Pernambuco [UFPE].

Leonam Costa Oliveira

E-mail: leonam_costa@yahoo.com.br / ORCID: http://orcid.org/0000-0003-4559-7202

Universidade Federal do Piauí - Brasil

Mestrado pelo Instituto de Medicina Integral [IMIP].

Jullyane Frazão Santana

E-mail: jullyanefrazao@ hotmail.com / ORCID: http://orcid.org/0000-0002-4537-7085

Universidade Federal do Piauí - Brasil

Graduanda em Pedagogia pela Universidade Federal do Piauí [UFPI]. 